\title{
Serum vitamin D deficiency in children and adolescents is associated with type 1 diabetes mellitus
}

\author{
Changwei Liu, Jingwen Wang, Yuanyuan Wan, Xiaona Xia, Jian Pan, Wei Gu and Mei Li \\ Children's Hospital of Nanjing Medical University, Nanjing, China \\ Correspondence should be addressed to C Liu: liuchangwei07@163.com
}

\begin{abstract}
Background: To investigate the relationship 25-hydroxy vitamin D (25OHD) level among children and in children with type 1 diabetes mellitus (T1DM).

Methods: A case-control study was conducted to compare the serum 250HD levels

between cases and controls. This study recruited 296 T1DM children (106 newly

diagnosed T1DM patients and 190 established T1DM patients), and 295 age- and gender-

matched healthy subjects as controls.

Results: The mean serum $250 \mathrm{HD}$ in T1DM children was $48.69 \pm 15.26 \mathrm{nmol} / \mathrm{L}$ and in the

controls was $57.93 \pm 19.03 \mathrm{nmol} / \mathrm{L}$. The mean serum 25OHD in T1DM children was lower than that of controls $(P<0.01)$. The mean serum $250 \mathrm{HD}$ level $(50.42 \pm 14.74 \mathrm{nmol} / \mathrm{L})$ in the newly diagnosed T1DM children was higher than that $(47.70 \pm 15.50 \mathrm{nmol} / \mathrm{L})$ in the established T1DM children but the difference was not statistically significant $(P=0.16)$. $\mathrm{HbA1c}$ values were associated with $250 \mathrm{HD}$ levels in established T1DM children $(r=0.264$, $P<0.01)$, and there was no association between 25OHD and HbA1C in newly diagnosed T1DM children $(r=0.164 ; P>0.05)$.

Conclusion: Vitamin D deficiency is common in T1DM children, and it should be worthy of attention on the lack of vitamin D in established T1DM children.
\end{abstract}

\author{
Key Words \\ - type 1 diabetes mellitus \\ - vitamin D \\ - insufficient
}

\section{Background}

Type 1 diabetes mellitus (T1DM) is an autoimmune disease occurring in the pancreatic islets. The disease can affect people of any age, but onset usually occurs in children or young adults, which accounts for $90 \%$ of diabetes in children and adolescents (1). The estimated incidence of type 1 diabetes per 100,000 persons years for all ages in China was 1.01 (2). However, the mean annual agestandardized incidence of type 2 diabetes in youth aged 5-19 years was 1.96/100,000 person-years (3).

Molecular mechanism of T1DM is unclear, which may be associated with many factors, such as gene and environment. T1DM is mainly caused by an autoimmune reaction, in which the body's defense system attacks the insulin-producing beta cells in the pancreas. The compelling https://doi.org/10.1530/EC-18-0191

(c) 2018 The authors Published by Bioscientifica Ltd evidence indicates that adaptive autoimmunity to the pancreatic beta cell is initially targeted against islet (4).

The major forms of vitamin $\mathrm{D}$ are vitamin D3, vitamin D2 and the active form of 1,25-(OH) 2D3. The active form of 1,25(OH)2D3 binds to vitamin D receptors (VDR), which is like other steroid hormones to a nuclear hormone receptor. VDR is a member of the nuclear transcription factor superfamily and is detected in most tissues. Through activation by $1,25(\mathrm{OH}) 2 \mathrm{D} 3$, VDR could be associated with the retinoid $\mathrm{X}$ receptor and binds to vitamin $\mathrm{D}$ response element in target gene for regulation of expression. In those nonclassical tissues, vitamin D shows potent antiproliferative and immunomodulatory properties (5).

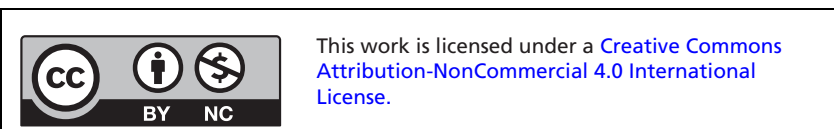


A lot of evidence has revealed that $1,25(\mathrm{OH}) 2 \mathrm{D} 3$ is closely related to the occurrence of autoimmune diseases $(6,7)$. Vitamin D can inhibit inflammation and immune reaction, promote synthesis and secretion of insulin and increase insulin sensitivity (8). A review has revealed that vitamin D deficiency has a potential influence on T1DM incidence, complications and progression (9). 25OHD is hydroxylated by the kidneys to form $1,25(\mathrm{OH}) 2 \mathrm{D} 3$. Thus, 25 OHD is usually measured in serum to determine a person's vitamin D status (10), and 25OHD is further hydroxylated by the kidneys to form 1,25(OH)2D3. Here, we aim to investigate the relationship between the serum 25 OHD and type 1 diabetes in local hospital.

\section{Materials and methods}

A total of 296 cases, including 106 newly diagnosed T1DM patients and 190 established T1DM patients, were recruited from Nanjing Medical University Affiliated Children's Hospital. A total of 295 nondiabetic controls were recruited. The selection of controls was random; they were outpatients of nondiabetic unit and were matched for age, gender and ethnicity. The exclusion criteria of controls included subjects who had conditions of bones, kidneys, liver, endocrinopathies, other autoimmune diseases or melanoma - all diseases that might influence vitamin metabolism. The study was approved by Nanjing Medical University Ethical Committee. Consent was obtained from each patient.

\section{Sample size and randomization}

The sample size was calculated by online power and sample size calculators (http://www.powerandsamplesize. $\mathrm{com} /$ ). Based on the previous study (11), we estimated the sample size for our study. If the power equaled 0.9 , the minimum sample size was about 42 . Our study met the minimum sample size. The stratification randomization method was conducted in this case-control study.

\section{Collection and processing of samples}

About $5 \mathrm{~mL}$ blood were collected from all the study subjects in appropriate tubes for subsequent laboratory analyses. The blood was drawn from patients when they were first diagnosed with T1DM or when the diagnosed patients came to the hospital once again. The serum was isolated from samples collected in plain tubes and stored at $-80^{\circ} \mathrm{C}$ for subsequent analyses.

\section{Measurement of $250 \mathrm{HD}$}

The levels of $25 \mathrm{OHD}$ in the serum were determined in T1DM patients and non-diabetic controls (296 patients and 295 controls respectively) using a non-radioactive Enzyme Immunoassay kit (EIA kit, Immuno-Diagnostic Systems Ltd. Boldon, UK, www.idsplc.com). This method used 'Direct' assay technology, which eliminated the solvent precipitation and centrifugation steps, thus resulting in the automation of the ELISA procedure. It has been shown to possess excellent sensitivity $(5 \mathrm{nmol} / \mathrm{L})$ from a small sample size $(25 \mu \mathrm{L})$ and a wide assay range $(6-360 \mathrm{nmol} / \mathrm{L})$. At concentrations of 15 and $80 \mathrm{nmol} / \mathrm{L}$ within-run CVs were 3.2 and $1.3 \%$ and total CVs were 5.3 and $3.1 \%$. Furthermore, this method eliminated the need for using a radioactive tracer. Appropriate controls were included in all assays for standardization and quality control.

The panel recommends the following classification of vitamin D status, based on serum 25OHD levels: sufficiency, $>50 \mathrm{nmol} / \mathrm{L}$; insufficiency, $30-50 \mathrm{nmol} / \mathrm{L}$; deficiency, $<30 \mathrm{nmol} / \mathrm{L}(12)$.

\section{Statistical analysis}

The data were analyzed using the Statistical Package for the Social Sciences, version 19 (SPSS). Normative distribution of data was tested by P-Plot. All data were normally distributed. Student $t$-test was used to compare the serum vitamin D between two groups. Chi-square test was

Table 1 Characteristics of T1DM study participants.

\begin{tabular}{|c|c|c|c|c|c|}
\hline & & Controls $(n=295)$ & Total T1DM $(n=296)$ & Newly diagnosed T1DM $(n=106)$ & Established T1DM $(n=190)$ \\
\hline \multirow{2}{*}{ Gender } & Males & 148 & 147 & 49 & 98 \\
\hline & Female & 147 & 149 & 57 & 92 \\
\hline Age (year) a & & $8.40 \pm 3.60$ & $8.66 \pm 3.75$ & $7.18 \pm 3.61$ & $9.49 \pm 3.58$ \\
\hline \multirow[t]{3}{*}{ Year } & $<6$ & 76 & 68 & 39 & 29 \\
\hline & $6-12$ & 16 & 166 & 59 & 107 \\
\hline & $>12$ & 57 & 62 & 8 & 54 \\
\hline
\end{tabular}

aValues are expressed as mean \pm S.D., Student $t$-test was used, $P<0.05$ was statistically significant.

$$
\begin{aligned}
& \text { https://ec.bioscientifica.com } \\
& \text { https://doi.org/10.1530/EC-18-0191 } 2018 \text { The authors }
\end{aligned}
$$


Table 2 Serum 25OHD level ( $\mathrm{nmol} / \mathrm{L})$.

\begin{tabular}{|c|c|c|c|c|}
\hline & Controls $(n=295)$ & Total T1DM $(n=296)$ & Newly diagnosed T1DM $(n=106)$ & Established T1DM $(n=190)$ \\
\hline Overalla & $57.93 \pm 19.03$ & $48.69 \pm 15.26$ & $50.42 \pm 14.74$ & $47.70 \pm 15.50$ \\
\hline$<6$ years $^{a}$ & $56.91 \pm 21.56$ & $52.92 \pm 13.48$ & $54.27 \pm 12.60$ & $51.00 \pm 14.67$ \\
\hline $6-12$ years $^{a}$ & $58.38 \pm 18.07$ & $49.40 \pm 15.18$ & $48.67 \pm 15.10$ & $49.82 \pm 15.28$ \\
\hline$>12$ years $^{a}$ & $58.00 \pm 18.36$ & $42.16 \pm 15.43$ & $44.35 \pm 19.03$ & $41.83 \pm 15.01$ \\
\hline
\end{tabular}

${ }^{a}$ Values are expressed as mean \pm s.D. ANOVA was used to compare vitamin D concentrations among subgroups. $P<0.05$ was statistically significant.

used to compare T1DM distribution between subgroups. ANOVA was used to compare vitamin D concentrations among subgroups in T1DM patients. $P$ value less than 0.05 was considered statistically significant.

\section{Results}

In this study, there were 296 T1DM children, including 106 children newly diagnosed T1DM and 190 children established T1DM and 295 controls. Selected characteristics are described in Table 1. The mean age of subjects in the T1DM children group was $8.66 \pm 3.75$ years and that of the control group was $8.40 \pm 3.60$ years respectively (the difference was not statistically significant; $t=0.847$, $P=0.398)$.

'Newly diagnosed diabetes' indicated duration of diabetes of 30 days or less, and 'established diabetes' indicated children with T1DM of duration longer than 30 days. The mean serum 25OHD of subjects in the total T1DM children group (newly diagnosed T1DM and established T1DM combined) was lower than that of the control group $(48.69 \pm 15.26 \mathrm{nmol} / \mathrm{L}$ vs $57.93 \pm 19.03 \mathrm{nmol} / \mathrm{L}$ ) (see Table 2). The serum mean $25 \mathrm{OHD}$ level was $50.42 \pm 14.74 \mathrm{nmol} / \mathrm{L}$ in the newly diagnosed T1DM group and was $47.70 \pm 15.50 \mathrm{nmol} / \mathrm{L}$ in the established T1DM group (Table 2), and the difference was not statistically significant $(t=1.482, \quad P=0.16)$. Vitamin deficiency increased with age in the T1DM patients but not so in the controls. The vitamin D status in T1DM and controls were showed in Table 3. In the total T1DM children, the deficient group was $13.18 \%$ (39/296), the insufficient group was 36.48\% (108/296), and the deficient and insufficient subgroup was $49.66 \%$ $(147 / 296)$, while in the control group, the deficient group was $5.76 \%(17 / 297)$, the insufficient group was $24.75 \%$ (73/295), and the deficient and insufficient subgroup was $30.51 \%$ (90/295). The difference between total T1DM and control in the deficient and insufficient subgroups was statistically significant $\left(\chi^{2}=24.27, P=0.00\right)$.

In the newly diagnosed T1DM children, the deficient group was $21.70 \%(23 / 106)$, the insufficient group was $42.45 \%(45 / 106)$, and the deficient and insufficient was $64.2 \%(68 / 106)$, while in the established T1DM, the deficient and insufficient subgroup was $41.60 \%$ (79/190). The difference between newly diagnosed T1DM and established T1DM in the deficient and insufficient subgroups was statistically significant $\left(\chi^{2}=13.86, P=0.00\right)$.

The seasonal distribution of mean serum vitamin $D$ levels in T1DM and controls is revealed in Table 4. The seasons were divided into summer months (April-September) and winter months (October-March) to analyze the serum 25OHD levels from T1DM and controls during different months of the year. The serum 25OHD level of T1DM was lower than those of controls only in the summer months $(t=-6.50, P=0.00)$.

HbA1c values were associated with 25OHD levels in established T1DM (Fig. 1) ( $r$ : 0.264, $P<0.01$ ), and there was no association between $25 \mathrm{OHD}$ and HbA1c in newly diagnosed T1DM $(r=0.164 ; P=0.09)$.

\section{Discussion}

In our study, T1DM children had lower mean 25OHD level than controls, $49.66 \%$ of T1DM childen were $25 \mathrm{OHD}$ insufficient, while the controls were $30.51 \%$.

Table 3 The vitamin D status in T1DM and controls.

\begin{tabular}{|c|c|c|c|c|}
\hline & Controls $(n=295)$ & Total T1DM $(n=296)$ & Newly diagnosed T1DM $(n=106)$ & Established T1DM $(n=190)$ \\
\hline Deficient group & 17 & 39 & 23 & 16 \\
\hline Insufficient group & 73 & 108 & 45 & 63 \\
\hline Sufficient group & 205 & 149 & 38 & 111 \\
\hline
\end{tabular}

Note: Chi-square test was used to compare T1DM distribution between subgroups, $P<0.05$ was statistically significant.

$$
\begin{aligned}
& \text { https://ec.bioscientifica.com } \\
& \text { https://doi.org/10.1530/EC-18-0191 } 2018 \text { The authors }
\end{aligned}
$$


Table 4 Serum 25OHD level ( $\mathrm{nmol} / \mathrm{L}$ ) in T1DM in difference season.

\begin{tabular}{|c|c|c|c|c|c|c|}
\hline \multirow[b]{2}{*}{ Season } & \multicolumn{2}{|l|}{ T1DM } & \multicolumn{2}{|l|}{ Controls } & \multirow[b]{2}{*}{$t$} & \\
\hline & $25 \mathrm{OHD}$ & $n$ & $25 \mathrm{OHD}$ & $n$ & & $\boldsymbol{P}$ \\
\hline $\begin{array}{c}\text { Summer } \\
\text { months }^{\mathrm{a}}\end{array}$ & $\overline{50.43 \pm 15.21}$ & $\overline{188}$ & $\overline{61.42 \pm 18.63}$ & 229 & -6.50 & 0.00 \\
\hline $\begin{array}{l}\text { Winter } \\
\text { months }^{\mathrm{a}}\end{array}$ & $45.66 \pm 14.93$ & 108 & $45.80 \pm 15.07$ & 66 & -0.06 & 0. \\
\hline
\end{tabular}

aValues are expressed as mean \pm S.D. Student $t$-test was used to compare the serum vitamin $D$ between two groups. $P<0.05$ was statistically significant.

The difference was statistically significant. In the newly diagnosed T1DM children, the deficient and insufficient was $64.2 \%$, while in the established T1DM, the subgroup was $41.60 \%$. $1,25-(\mathrm{OH}) 2 \mathrm{D} 3$, as the active metabolite of vitamin D3, is known for the maintenance of mineral homeostasis and normal skeletal architecture and is being increasingly recognized for their potent antiproliferative, prodifferentiative and immunomodulatory activities (13). Vitamin D, known to exhibit immunomodulatory properties and prevent the development of type 1 diabetes in NOD mice, is efficient against apoptosis induced by cytokines in human pancreatic islets in vitro (14). It inhibits the differentiation and maturation of dendritic cells and promotes their apoptosis, preventing their transformation into antigen-presenting cells, which is the first step in the initiation of an immune response (9). Mice with diet-induced hypovitaminosis D led impaired glucose tolerance, increased RAS component expression and impaired islet function gene transcription (15). Vitamin D may play a role in pancreatic disease, including

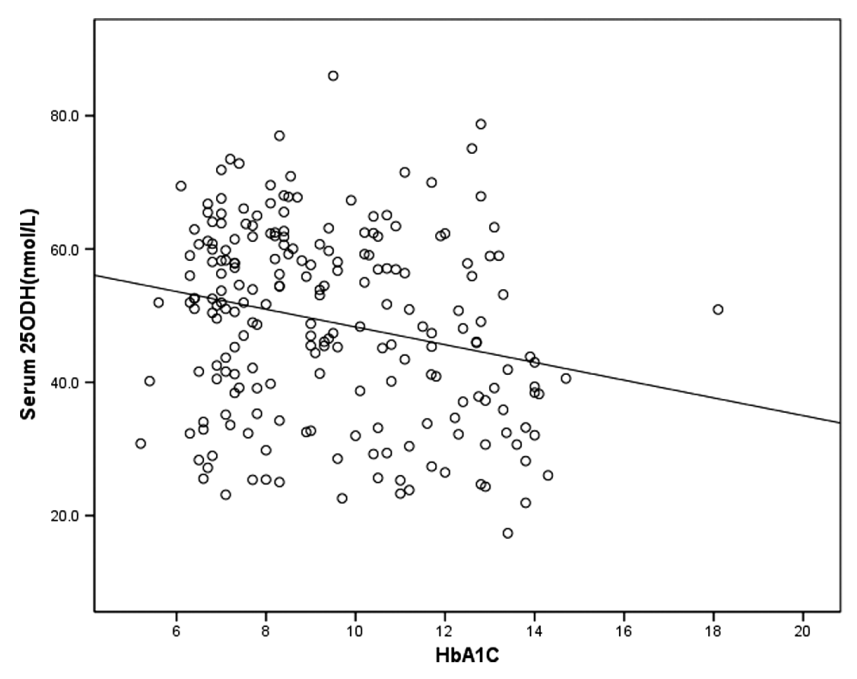

Figure 1

Linear correlation between serum 250HD level and hemoglobin A1c in established T1DM. type 1 and type 2 diabetes mellitus as well as pancreatic cancer (16).

In a cross-sectional study, $60-84 \%$ of T1DM children were 25OHD deficient in Switzerland (17), and 90.6\% of T1DM children vs $85.3 \%$ of nondiabetic children had vitamin D deficiency in North Indian in a case control study (18). It had been indicated that $15 \%$ of T1DM patients were 25OHD deficient and 61\% were insufficient in Northeastern US in a cross-sectional study (18). Furthermore, all these data manifested significantly lower mean 25OHD level in T1DM children compared to controls (19). These have suggested that low serum vitamin D level is associated with T1DM in children (20).

Previous study has revealed that the serum 25OHD concentrations are not associated with the development of T1DM in Finland (21). However, severe ketoacidosis, as judged by bicarbonate may have transiently lower 25OHD levels in children with new-onset type 1 diabetes (22). Vitamin D supplementation can improve glycemic control (23). Children with T1DM may have 25OHD deficiency, which had an effect on metabolic status and glycemic homeostasis.

In our study, HbA1c was associated with 25OHD levels in established T1DM.

In a randomized, double-blind, placebo-controlled trial, 30 young patients with new-onset T1DM assigned to cholecalciferol or placebo for 12 months, showed that cholecalciferol improved suppressor function of Treg in patients with T1DM and vitamin D could serve as one possible agent in the development of immunomodulatory combination therapies for T1DM (24).

There are also some strengths and limitations of our study. The merit of our study is in the analysis of the mean 25OHD between controls and newly diagnosed T1DM children. Additionally, some limitations also exist in this preliminary study. Deep studies on molecular mechanism are needed in future work.

In conclusion, T1DM children have lower 25OHD than controls, and the serum vitamin D levels were found to be significantly different in early-onset and late-onset T1DM children. Whether low vitamin D is a risk factor or consequence of T1DM is still to be deeply researched.

\section{Declaration of interest}

The authors declare that there is no conflict of interest that could be perceived as prejudicing the impartiality of the research reported.

\section{Acknowledgement}

This study was supported by medical science and technology development foundation (No. YKK14119). 


\section{References}

1 Craig ME, Hattersley A \& Donaghue KC. Definition, epidemiology and classification of diabetes in children and adolescents. Pediatric Diabetes 200910 (Supplement 12) 3-12. (https://doi.org/10.1111/ j.1399-5448.2009.00568.x)

2 Weng J, Zhou Z, Guo L, Zhu D, Ji L, Luo X, Mu Y \& Jia W. Incidence of type 1 diabetes in China, 2010-13: population based study. BMJ 2018360 j5295. (https://doi.org/10.1136/bmj.j5295)

3 Wu H, Zhong J, Yu M, Wang H, Gong W, Pan J, Fei F, Wang M, Yang $\mathrm{L} \& \mathrm{Hu}$ R. Incidence and time trends of type 2 diabetes mellitus in youth aged 5-19 years: a population-based registry in Zhejiang, China, 2007 to 2013. BMC Pediatrics 201717 85. (https://doi. org/10.1186/s12887-017-0834-8)

4 Itoh A \& Ridgway WM. Targeting innate immunity to downmodulate adaptive immunity and reverse type 1 diabetes. ImmunoTargets and Therapy 20176 31-38. (https://doi.org/10.2147/ITT.S117264)

5 Muñoz GA, Kutmon M, Eijssen L, Hewison M, Evelo CT \& Coort SL. Pathway analysis of transcriptomic data shows immunometabolic effects of vitamin D. Journal of Molecular Endocrinology 201860 95-108. (https://doi.org/10.1530/JME-17-0186)

6 Liu W, Li H, Hao Y, Li Y, Lv M, Xue F, Liu X, Zhang L \& Yang R. Decreased immunosuppressive actions of $1 \alpha, 25$-dihydroxyvitamin D3 in patients with immune thrombocytopenia. Molecular Immunology 201678 89-97. (https://doi.org/10.1016/j. molimm.2016.08.014)

7 Shirazi HA, Rasouli J, Ciric B, Wei D, Rostami A \& Zhang GX. 1,25-Dihydroxyvitamin D3 suppressed experimental autoimmune encephalomyelitis through both immunomodulation and oligodendrocyte maturation. Experimental and Molecular Pathology 2017102 515-521. (https://doi.org/10.1016/j. yexmp.2017.05.015)

8 Fayed A, El NMM, Heikal AA, Abdulazim DO, Naguib MM, UAA SED. Fibroblast growth factor-23 is a strong predictor of insulin resistance among chronic kidney disease patients. Renal Failure 201840 226-230. (https://doi.org/10.1080/0886022X.2018.1455594)

9 Chakhtoura M \& Azar ST. The role of vitamin d deficiency in the incidence, progression, and complications of type 1 diabetes mellitus. International Journal of Endocrinology 20132013148673. (https://doi.org/10.1155/2013/148673)

10 Hollis BW. Assessment of vitamin D nutritional and hormonal status: what to measure and how to do it. Calcified Tissue International 1996 58 4-5. (https://doi.org/10.1007/BF02509538)

11 Bae KN, Nam HK, Rhie YJ, Song DJ \& Lee KH. Low levels of 25-hydroxyvitamin $\mathrm{D}$ in children and adolescents with type 1 diabetes mellitus: a single center experience. Annals of Pediatric Endocrinology and Metabolism 201823 21-27. (https://doi. org/10.6065/apem.2018.23.1.21)

12 Munns CF, Shaw N, Kiely M, Specker BL, Thacher TD, Ozono K, Michigami T, Tiosano D, Mughal MZ, Mäkitie O, et al. Global Consensus Recommendations on Prevention and Management of Nutritional Rickets. Journal of Clinical Endocrinology and Metabolism 2016101 394-415. (https://doi.org/10.1210/jc.20152175)
13 Nagpal S, Na S \& Rathnachalam R. Noncalcemic actions of vitamin D receptor ligands. Endocrine Reviews 200526 662-687. (https://doi. org/10.1210/er.2004-0002)

14 Riachy R, Vandewalle B, Moerman E, Belaich S, Lukowiak B, Gmyr V, Muharram G, Kerr CJ \& Pattou F. 1,25-Dihydroxyvitamin D3 protects human pancreatic islets against cytokine-induced apoptosis via down-regulation of the Fas receptor. Apoptosis 200611 151-159. (https://doi.org/10.1007/s10495-006-3558-z)

15 Cheng Q, Boucher BJ \& Leung PS. Modulation of hypovitaminosis D-induced islet dysfunction and insulin resistance through direct suppression of the pancreatic islet renin-angiotensin system in mice. Diabetologia 201356 553-562. (https://doi.org/10.1007/s00125-0122801-0)

16 Altieri B, Grant WB, Della CS, Orio F, Pontecorvi A, Colao A, Sarno G \& Muscogiuri G. Vitamin D and pancreas: The role of sunshine vitamin in the pathogenesis of diabetes mellitus and pancreatic cancer. Critical Reviews in Food Science and Nutrition $2017 \mathbf{5 7}$ 3472-3488. (https://doi.org/10.1080/10408398.2015.1136922)

17 Janner M, Ballinari P, Mullis PE \& Flück CE. High prevalence of vitamin D deficiency in children and adolescents with type 1 diabetes. Swiss Medical Weekly 2010140 w13091. (https://doi. org/110.4414/smw.2010.13091)

18 Borkar VV, Devidayal, Verma S \& Bhalla AK. Low levels of vitamin $\mathrm{D}$ in North Indian children with newly diagnosed type 1 diabetes. Pediatric Diabetes 201011 345-350. (https://doi.org/10.1111/j.1399. 5448.2009.00589.x)

19 Rasoul MA, Al-Mahdi M, Al-Kandari H, Dhaunsi GS \& Haider MZ. Low serum vitamin-D status is associated with high prevalence and early onset of type-1 diabetes mellitus in Kuwaiti children. BMC Pediatrics 201616 95. (https://doi.org/10.1186/s12887-016-0629-3)

20 Liu C, Lu M, Xia X, Wang J, Wan Y, He L \& Li M. Correlation of serum vitamin D level with type 1 diabetes mellitus in children: a meta-analysis. Nutricion Hospitalaria 201532 1591-1594. (https://doi. org/10.3305/nh.2015.32.4.9198)

21 Mäkinen M, Mykkänen J, Koskinen M, Simell V, Veijola R, Hyöty H, Ilonen J, Knip M, Simell O \& Toppari J. Serum 25-hydroxyvitamin D concentrations in children progressing to autoimmunity and clinical type 1 diabetes. Journal of Clinical Endocrinology and Metabolism 2016 101 723-729. (https://doi.org/10.1210/jc.2015-3504)

22 Devidayal, Singh MK, Sachdeva N, Singhi S, Attri SV, Jayashree M \& Bhalla AK. Vitamin D levels during and after resolution of ketoacidosis in children with new onset Type 1 diabetes. Diabetic Medicine 201330 829-834. (https://doi.org/10.1111/dme.12200)

23 Savastio S, Cadario F, Genoni G, Bellomo G, Bagnati M, Secco G, Picchi R, Giglione E \& Bona G. Vitamin D deficiency and glycemic status in children and adolescents with type 1 diabetes mellitus. PLOS ONE 201611 e0162554. (https://doi.org/10.1371/journal. pone.0162554)

24 Treiber G, Prietl B, Fröhlich-Reiterer E, Lechner E, Ribitsch A, Fritsch M, Rami-Merhar B, Steigleder-Schweiger C, Graninger W, Borkenstein $\mathrm{M}$, et al. Cholecalciferol supplementation improves suppressive capacity of regulatory T-cells in young patients with new-onset type 1 diabetes mellitus - A randomized clinical trial. Clinical Immunology 2015161 217-224. (https://doi.org/10.1016/j. clim.2015.08.002)

Received in final form 25 August 2018

Accepted 10 October 2018

Accepted Preprint published online 10 October 2018 https://ec.bioscientifica.com https://doi.org/10.1530/EC-18-0191

C 2018 The authors Published by Bioscientifica Ltd

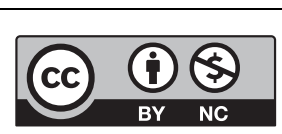

This work is licensed under a Creative Commons Attribution-NonCommercial 4.0 International License. 